\section{Profile of Resistance in the Retreatment Cases of Tubercu- losis: Microbiological Aspects}

\author{
Natacha N'takpe Kouame ${ }^{1 *}$, Kigninlman Horo², N'GUESSAN \\ Kouassi Raymond ${ }^{3}$, Karamoko Touré4, Cyriac Kouadio², \\ Danielle Assi ${ }^{4}$, Viviane Aney ${ }^{4}$, Ibrahima Coulibaly ${ }^{1}$ and \\ ADADE Kouakou ${ }^{5}$
}

\begin{abstract}
${ }^{1}$ Antituberculosis center of Yopougon, Abidjan, Ivory Coast ${ }^{2}$ Pneumology Service of the University Hospital of Cocody, Abidjan, Ivory Coast

${ }^{3}$ The Pasteur Institute of Microbiology Service, Abidjan, Ivory Coast ${ }^{4}$ Antituberculosis center of Adjamé, Abidjan, Ivory Coast
\end{abstract}

${ }^{5}$ National Program against Tuberculosis of Ivory Coast, Abidjan, Ivory Coast

\begin{abstract}
Emergence of Drug resistance is a nightmare for tuberculosis control programs and complex health care system in particular. Here we observe a strong link between drug resistance and a history of TB treatment.

The aim of present study is to describe the resistance profile among retreatment cases of tuberculosis in here comes the city or country.

\section{Methodology}

We conducted a retrospective survey on the analys is of records of patients starting tuberculos is retreatment for failure or relapse of tuberculosis. We used 193 records with culture results and drug susceptibility testing.

Results

The proportion of failure is $59 / 193(30.6 \%$ and the cases of relapse is $134 / 193(69.4 \%)$ in our study). The proportion of married life is $23.4 \%(11 / 47)$ in failure against $41.5 \%(51 / 123)$ in relapse of tuberculosis $[p=0,021, O R=0,431(0,201-0,927)]$. Patients failing therapy have more chest pain $[5,8 \%(3 / 52)$ versus $0 \%(0 / 126)$ avec $p=$ $0,024]$. The proportion of MDR-TB is $61.4(38 / 59)$ on failure against $41 \%(55 / 134)$ in case of relapse $[p=0.002, O R=2.599(1.378$ to 4.902)].

\section{Conclusion}

The proportion of the resistance is very important in retreatment cases. But most patients who have failed to TB.
\end{abstract}

*Corresponding author: Natacha N'takpe Kouame, Antituberculosis center of Yopougon, Abidjan, Ivory Coast, Tel: +225 59753094; E-mail: raissantakpe@yahoo.fr

Citation: Kouame NN, Horo K, Raymond NK, Touré K, Kouadio C, et al. (2017) Profile of Resistance in the Retreatment Cases of Tuberculosis: Microbiological Aspects. J Pulm Med Respir Res 3: 008.

Received: May 26, 2016; Accepted: March 15, 2017; Published: March 31, 2017
Keywords: Failure; Multidrug resistance; Relapse; Tuberculosis

\section{Introduction}

Drug resistance and especially the emergence of Multi-Drug Resistant Tuberculosis (MDR-TB) has become a global major public health problem. It thus impedes the effectiveness of measures for TB control strategies both globally and in Côte d'Ivoire. The rapid increase in multi-drug resistant tuberculosis which is defined as Mycobacterium tuberculosis resistant to atleast isoniazid and rifampicin (both most effective antituberculosis drugs) with or without resistance to other first-line drugs $[1,2]$, is the direct result of poor management of tuberculosis sensitive bacillus [3] failure by the patient of the risks of an out break of multi-resistant strain, or non-application of the technique of supervised treatment in patients at high risk of nonadherence [4]. The economic and social burden of this deadly disease is already evident. Treating a case of MDR-TB is more expensive, also more toxic to the patient [3] creating a load for both the patient and the health care system especially in developing countries. Retreatment cases are recognized as those patients who have already completed one or more anti-tuberculosis treatment for more than a month [5]. While resistance in these retreatment cases is observed in cultures and drug susceptibility assays. We observe a strong link between drug resistance and previously TB treatment $[1,6]$. In many countries, experience has shown that patients with active MDR-TB strains in their sputum can infect large numbersof people with HIV, rapidly causing outbreaks of MDR-TB with a high mortality rate $[7,8]$. It is therefore imperative to diagnose and support an early stage this particular form of tuberculosis to prevent the occurrence of a deadlock therapeutic. In this perspective, the objective of our study is to describe the resistance profile during retreatment TB to optimize prevention.

\section{Methodology}

\section{Part of the study}

The fight against tuberculosis is organized by the national fight against tuberculos is (PNLT) in Côte d'Ivoire through a technical guide [9]. The national technical guide contains recommendations and definitions that enable the organization monitoring and evaluation of the fight against tuberculosis in Ivory coast. Management tools in the fight are essentially laboratory records for TB microscopy, registry case report, the file of TB patients, and the treatment card of TB patients. This guide follows the definitions of (World Health Organization) (WHO) and International Union against Tuberculosis and Lung Disease (The UNION) $[9,10]$.

PTB+: Pulmonary Tuberculosis Smear Positive

\section{Retreatment cases include different situations}

Relapse patients: Are previously treated for TB, were declared cured or treatment completed at the end of their most recent treatment episode and are now diagnosed with a recurrent episode of TB (either a true relapse or a new episode of TB caused by reinfection). "Companion handbook to the 2011 WHO Guidelines for the Programmatic Management of Drug resistant Tuberculosis" 
Treatment after failure patients: Are previously treated for TB and whose treatment failed at the end of their most recent treatment episode.

Return after default: Those patients who interrupted treatment for 2 months or more and come back with a positive bacteriological evidence. Preventing TB-MR in this guide is based on the implementation of the DOTS strategy. In this guide, culture-antibiogram and susceptibility testing are recommended for patients who have failed treatment for TB for new TB cases, relapse of tuberculosis and rechallenge after abandonment. Cultures-susceptibility and sensitivity test is carried out by the reference laboratories like Mycobacterium laboratory of the Pasteur Institute in Abidjan and CeDReS. Incenters supported devices patients is kept records request crop susceptibility.

\section{Study type}

We conducted a retrospective study based on there trieval of records and patient records in TB centers Adjame and Yopougon, the two largest centers in tuberculosis control activities in Côte d'Ivoire. We audited the activity of crop susceptibility of 2012-2013.

\section{Selecting folders}

We selected records of patients who were started on reprocessing protocol (2RHZES/1RHZE/5RHE). The records of patients who received a prescription of crop susceptibility with the collection and delivery of two pots of sputum laboratory. We excluded records of patients whose culture-susceptibility is not available, as are files not found.

\section{Method}

\section{Preparation of the inoculum from a positive BACTEC MGIT 7} ml Tube:

Note: It is important to prepare the inoculum using the following time references to obtain the appropriate organism concentration for the susceptibility test.

1. The first day of an instrument positive MGIT tube is considered Day 0.

2. For the preparation of the test inoculum, a positive $7 \mathrm{ml}$ MGIT tube should be used the day after it first becomes positive on the BATEC MGIT instrument (Day 1), up to and including the fifth day (Day 5) after instrument positivity. A tube which has been positive longer than five days should be subcultured to a fresh $7 \mathrm{ml}$ MGIT tube containing BACTEC MGIT Growth Supplement and tested on the BACTEC MGIT instrument until positive, and used from one to five days following positivity. See "Preparation of a seed MGIT Tube from Liquide Media."

3. If the tube is a Day 1 or Day 2 positive, use the MGIT broth suspension for the inoculation procedures. Mix well. Proceed to "Inoculation Procedure for Susceptibility Test."

4. If the tube is a Day 3, Day 4, or Day 5 positive, mix well then dilute $1 \mathrm{ml}$ of the positive broth in $4 \mathrm{ml}$ of sterile saline (1:5 dilution). Mix tube thoroughly. Use the diluted suspension for the inoculation procedures. Proceed to "Inoculation Procedure for Susceptibility Test."

\section{Preparation of seed MGIT Tube from liquid Media:}

1. Mix the tube by inversion or vortexing.

2. Make a 1:100 dilution by adding $0.1 \mathrm{ml}$ of the culture in to $10 \mathrm{ml}$ of BBL Middlebrook 7H9 Broth or BBL MGIT Broth. Mix well.
3. Add $0.5 \mathrm{ml}$ of this suspension into a $7 \mathrm{ml}$ MGIT tube supplemented with $0.8 \mathrm{ml}$ of BACTEC MGIT Growth supplement.

4. Cap tightly and gently mix by inverting 2-3 times.

5. Enter the tube into a BACTEC MGIT instrument and test until positive.

Note: Time to positivity must be $\geq 4$ days for use as AST inoculum. If tube becomes positive in $<4$ days, return to step 1 and prepare a new seed tube.

6. This tube may now be used from one to five days following positivity. Proceed to "Preparation of the inoculum from a positive BACTEC MGIT $7 \mathrm{ml}$ tube" above.

\section{Inoculation procedure for BACTEC MGIT 960 SIRE Kit susceptibility test:}

1. Label five $7 \mathrm{ml}$ MGIT tubes for each test isolate. Label one as GC (Growth Control), one as STR, one as INH, one as RIF and one as EMB. Place the tubes in the correct sequence in the appropriate size AST set Carrier (see BACTEC MGIT instrument user's Manual).

2. Aseptically add $0.8 \mathrm{ml}$ of BACTEC MGIT SIRE Supplement to each tube. Note: It is important to use supplement supplied with the kit.

3. Aseptically pipet, using a micropipet, $100 \mu \mathrm{l}$ of $83 \mu \mathrm{g} / \mathrm{ml}$ MGIT RIF solution to the appropriately labeled MGIT tube. Aseptically pipet $100 \mu \mathrm{l}$ of $415 \mu \mathrm{g} / \mathrm{ml}$ MGIT EMB solution to the appropriately labeled MGIT tube. It is important to add the correct drug to the corresponding tube. No antibiotics should be added to the MGIT GC tube (Table 1).

\begin{tabular}{|c|c|c|c|}
\hline Drug & $\begin{array}{c}\text { Concentration } \\
\text { of drug after } \\
\text { reconstitution* }\end{array}$ & $\begin{array}{c}\text { Volume added to } \\
\text { MGIT tubes for test }\end{array}$ & $\begin{array}{c}\text { Final concentration } \\
\text { in MGIT tubes }\end{array}$ \\
\hline MGIT STR & $83 \mu \mathrm{g} / \mathrm{ml}$ & $100 \mu \mathrm{l}$ & $1.0 \mu \mathrm{g} / \mathrm{ml}$ \\
\hline MGIT INH & $8.3 \mu \mathrm{g} / \mathrm{ml}$ & $100 \mu \mathrm{l}$ & $0.1 \mu \mathrm{g} / \mathrm{ml}$ \\
\hline MGIT RIF & $83 \mu \mathrm{g} / \mathrm{ml}$ & $100 \mu \mathrm{l}$ & $1.0 \mu \mathrm{g} / \mathrm{ml}$ \\
\hline MGIT EMB & $415 \mu \mathrm{g} / \mathrm{ml}$ & $100 \mu \mathrm{l}$ & $5.0 \mu \mathrm{g} / \mathrm{ml}$ \\
\hline \multicolumn{4}{|c|}{ Table 1: Drug Concentration and Volume Preparation. } \\
\hline
\end{tabular}

4. These drugs must be reconstituted using $4 \mathrm{ml}$ sterile/deionized water to achieve concentrations indicated.

5. Growth control tube preparation and inoculation: Aseptically pipet $0.5 \mathrm{ml}$ of the organism suspension (see "Inoculum Preparation") into $10 \mathrm{ml}$ of sterile saline to prepare the 1:100 Growth control suspension into the MGIT tube labeled "GC."

6. Drug-containing tube inoculation: Aseptically pipet $0.5 \mathrm{ml}$ of the organism suspension (see "Inoculation Preparation") into each of the four remaining drug tubes (STR, INH, RIF, EMB).

7. Tight recap the tubes. Mix tubes thoroughly by gentle inversion for three to four times.

8. Enter the AST set into the BACTEC MGIT instrument using the AST set entry feature (refer to the BATEC MGIT instrument user's Manuel). Ensure that the order of tubes AST set carrier conforms to the set carrier definitions selected when performing the AST set entry feature.

9. Streak $0.1 \mathrm{ml}$ of the organism suspension to a Trypticase Soy Agar with $5 \%$ sheep blood (TSA 2) plate. Enclose in a plastic bag. Incubate at $35-37^{\circ} \mathrm{C}$. 
10. Check the blood agar plate at $48 \mathrm{~h}$ for bacterial contamination. If the blood agar plate shows growth, discard the AST set (refer to the BACTEC MGIT instrument user's Manual) and repeat testing with pure culture.

\section{Parameters and data analyses}

The parameters of our study were socio-demographicparameters (age, sex, occupation, place of residence, religion, married life, medical history, respiratory signsat diagnosis, bacteriological diagnosis of tuberculosis, HIV status, clinical bacteriological monitoring and treatment outcome).

\section{Results}

In our study population, the proportion of failures in retreatment the cases were 59/193(30.6\%) and relapse cases were 134/193 (69.4\%). The proportion of MDR-TB is $61.4(38 / 59)$ in case of failure against $41 \%(55 / 134)$ in case of relapse $[\mathrm{p}=0.002, \mathrm{OR}=2.599(1.378$ to 4.902$)$ ].

The proportion of patients experiencing failure and relapse is $140 / 193(72.5 \%)$ in men and 53/193 (27.5\%) in women, the resistance profile of 93 (48,2\%) cases of MDR-TB, 72 (37.3\%) cases susceptible to Mycobacterium tuberculosis, 15 (7.8\%) mono-resistant and 13(6.7\%) of poly-resistance case. Cases of mono-resistance to rifampicin are 6 in number $(3.1 \%), 8(4.1 \%)$ for isoniazid, $1(0.5 \%)$ to isoniazid associated with ethambutol $1(0.5 \%)$ for ethambutol and streptomycin, $1(0.5 \%)$ both rifampicin, ethambutol and streptomycin, $1(0.5 \%)$ both isoniazid, ethambutol and streptomycin (Table 2).

\begin{tabular}{|c|c|c|}
\hline & Number & Frequency \\
\hline \multicolumn{3}{|l|}{ Drugs } \\
\hline \multicolumn{3}{|c|}{ Mono-resistance } \\
\hline $\mathrm{R}$ & 6 & $3.8 \%$ \\
\hline $\mathrm{H}$ & 8 & $4.1 \%$ \\
\hline Total & 14 & $7.2 \%$ \\
\hline \multicolumn{3}{|l|}{$\mathrm{R}+\mathrm{H}$ resistant } \\
\hline \multicolumn{3}{|l|}{ MDR-TB } \\
\hline $\mathrm{RH}$ & 70 & $3.63 \%$ \\
\hline RHS & 1 & $0.5 \%$ \\
\hline RHES & 8 & $4.1 \%$ \\
\hline Total & 79 & $40.9 \%$ \\
\hline \multicolumn{3}{|l|}{ Other resistant } \\
\hline $\mathrm{HE}$ & 1 & $0.5 \%$ \\
\hline ES & 1 & $0.5 \%$ \\
\hline RES & 1 & $0.5 \%$ \\
\hline Total & 3 & $1.5 \%$ \\
\hline \multicolumn{3}{|c|}{ Table 2: Resistance to TB drugs. } \\
\hline \multicolumn{3}{|c|}{$\mathrm{R}=$ Rifampicin; $\mathrm{H}=$ Isoniazid; $\mathrm{E}=$ Ethambutol; $\mathrm{S}=$ Streptomycin } \\
\hline
\end{tabular}

\section{Discussion}

The audit of 193 cases with - susceptibility culture has enabled us to note that cases of retreatment TB are mostly made of the young adult subjects, male experiencing recurrent TB (Table 2). Represented male (72.5\%), this number is near to found that by B. Kouassi and collaborator (73\%); A study in Burkina Faso found that (68\%) were male.

In the epidemiology of $\mathrm{TB}$, male dominance has been reported by other studies; it could result from differences in exposure between male and female in their societal role, that is to say, differences in relation to their activities [11]; men occupy different industries, facilitating the transmission of TB $[12,13]$. The proportion of relapse was 69.4\% lower than that found in Morocco (74\%) [14] against 30.6 inchess. The high proportion of relapse may be explained by the fact that some bacilli remained alive in the human lungs alveoli and are reactivated later following a failure of the body. It is hypothesized that in reality these relapses may be undetected failures. However, the rate of MDR-TB was higher in failures (61.4\%) higher than that observed in Camero on (57.1\%) [15].

The proportion of MDR-TB during reprocessing observed in our study (48.2\%) is lower than in 2004 (79\%) observed in hospital pneumologic environment in Abidjan [16,17].

This can be explained by our sample and the fact that the data relates only to anti-TB centers, Ivory Coast. Forson and collaborator-have found a lower value in Ghana (36\%) [18], African Countries-other also have reported about lower rates: $11.1 \% 25.5 \%$ in Benin [19] Rwanda [20].

The rate of mono rifampicin resistance was observed (3.1\%) lower than that observed in Rwanda (8.1\%) but higher than that observed in Benin (2.2\%) and Ethiopia (1.3\%). And rate of mono isoniazid resistance $(4.1 \%)$ is higher than that observed in Madagascar (3.9\%) and Senegal (2.4\%) but lower than that observed in Benin (9.3\%) and Tanzania $(10.2 \%)$.

Although the rate of co-infection TB-HIV is high among our patients, MDR-TB was not correlated with HIV infection: this corroborates the results of other African studies [21,22]. Patients, according to a bacteriological perspective, may be suffering from MDR-TB are usually on the ground the patients classified as failures of Category II of the WHO (2RHZES/1RHZE/5RHE). Patients with both plans (Categories I and II) containing RMP led to a failure (which the latter received the RMP for atleast 8 months) are likely to have MDR-TB and are more than $85 \%$ of case [23].

This group runs the highest risk of MDR-TB and should be a priority for the molecular test sensitivity. The tragedy is that although patients detected, the treatment remain stardy and drug supplies are in sufficient in our country due to resource limitations and high burden as well [24]. Similarly we observed that at the time of the conduct of the treatment the some patients were already suffering from a cute respiratory failure which causes the patient's death even before completing his treatment [25]. The multidrug-resistant tuberculosis in Côte d'Ivoire is taking serious proportions and affects all age groups including children. Despite the significant decrease in the primary transmission in 2006 (2.5\%) [26] MDR-TB remains difficult to control in Ivory Côte d'ivoire of without specialized center for MDR-TB.

\section{Conclusion}

MDR-TB is the result of the therapeutic anarchy and lack of adherence to treatment of patients. Most at risk are health care workers who are not always trained in infection control and biosafety/biosecurity concepts.

The National Program Fight against Tuberculosis should strengthen the protection of laboratory workers who are exposed to aerosols by making their provisions respirators when handling.

The possibility of a quick and accurate diagnosis is the cornerstone of a strong National Program Fight against Tuberculosis. Before you can effectively treat drug-resistant $\mathrm{TB}$, we must first correct diagnosis. 
Citation: Kouame NN, Horo K, Raymond NK, Touré K, Kouadio C, et al. (2017) Profile of Resistance in the Retreatment Cases of Tuberculosis: Microbiological Aspects. J Pulm Med Respir Res 3: 008.

Although new molecular technologies such as reverse hybridization of molecular probes online and Xpert ${ }^{\oplus} \mathrm{MTB} / \mathrm{RIF}$, allow rapid diagnosis of thousands of cases of MDR-TB, all countries will not be able to handle these cases by applying the appropriate guidelines. Obviously, this poses a risk of generating extremely drug resistant form of $\mathrm{TB}$ which is called XDR.

\section{References}

1. World Health Organization (2008) The WHO/IUATLD Global Project on Anti-Tuberculosis Drug Resistance Surveillance. Anti-tuberculosis drug Resistance in the world, Geneva, Switzerland.

2. Espinal MA, Kim SJ, Suarez PG, Kam KM, Khomenko AG, et al. (2000) Standard short-course chemotherapy for drug-resistant tuberculosis. Treatment out-comes in 6 countries. JAMA 283: 2537-2545.

3. World Health Organization (2008) Guidelines for the programmatic management of drug-resistant tuberculosis. World Health Organization, Geneva, Switzerland.

4. Crofton J, Chaulet P, Maher D (1997) Guidelines for the management of drug resistant tuberculosis. World Health Organization, Geneva, Switzerland.

5. Burgos M, Gonzalez LC, Paz EA, Gournis E, Kawamura LM, et al. (2005) Treatment of multidrug-resistant tuberculosis in San Francisco: an outpatient-based approach. Clin Infect Dis 40: 968-975.

6. World Health Organization (2004) The WHO/IUATLD Global Project on Anti-Tuberculosis Drug Resistance Surveillance. Anti-Tuberculosis Drug Resistance in the world, Geneva, Switzerland.

7. Mac-Arthur A, Gloyd S, Perdigão P, Noya A, Sacarlal J, et al. (2001) Characteristics of drug resistance and HIV among tuberculosis patients in Mozambique. Int J Tuberc Lung Dis 5: 894-902.

8. Gorin FM, Nelson ET, Matts JP, Cohn DL, Ernst J, et al. (1996) The impact of human immunodeficiency virus infection on drug-resistant tuberculosis. Am J Respir Crit Care Med 154: 1478-1483.

9. Programme National de Lutte contre la Tuberculose (2005) Guide technique de la composante tuberculose direction exécutive service tuberculose. Abidjan, Ivory Coast.

10. Raviglione M (2001) Révisions des définitions internationales pour la lutte contre la tuberculose. Int J Tuberc Lung Dis 5 : 213-215.

11. Holmes CB, Hausler $H$, Nunn $P$ (1998) A review of sex differences in the epidemiology of tuberculosis. Int J Tuberc Lung Dis 2: 96-104.

12. Kouassi B, Horo K, N'douba KA, Koffi N, Ngom A, et al. (2004) [Epidemiological, clinical and biological profile of resistant or recurrent pulmonary tubercuIosis in Abidjan]. Bull Soc Pathol Exot 97: 336-337.

13. Sangaré L, Diandé S, Badoum G, Dingtoumda B, Traoré AS (2010) Anti-tuberculosis drug resistance in new and previously treated pulmonary tuberculosis cases in Burkina Faso. Int J Tuberc Lung Dis 14: 1424-1429.
14. Dooley KE, Lahlou O, Ghali I, Knudsen J, Elmessaoudi MD, et al. (2011) Risk factors for tuberculosis treatment failure, default, or relapse and outcomes of retreatment in Morocco. BMC Public Health 11: 140.

15. Schreiber YS, Herrera AF, Wilson D. Wallengren K, Draper R (2009) Tuberculosis retreatment category predicts resistance in hospitalized retreatment patients in a high HIV prevalence area. Int J Tuberc Lung Dis 13: 1274-1280.

16. Danguy-Aka E, Kouassi Boko A, N'gom A, Koffi N, Tchamran M, et al. (2000) des malades tuberculeux en situation d'échec ou de rechute à Abidjan. Rev Mal Resp 17: 121.

17. Kouassi B, Horo K, N'douba KA, Koffi N, Ngom A, et al. (2004) [Epidemiological, clinical and biological profile of resistant or recurrent pulmonary tuberculosis in Abidjan]. Bull Soc Pathol Exot 97: 336-337.

18. Forson A, Kudzawu S, Kwara A, Flanigan T (2010) High Frequency of FirstLine Anti-Tuberculosis Drug Resistance among Persons with Chronic Pulmonary Tuberculosis at a Teaching Hospital Chest Clinic. Ghana Med J 44: 42-46.

19. Affolabi D, Adjagba OA, Tanimomo-Kledjo B, Gninafon M, Anagonou SY, et al. (2007) Anti-tuberculosis drug resistance among new and previously treated pulmonary tuberculosis patients in Cotonou, Benin. Int $\mathrm{J}$ Tuberc Lung Dis 11: $1221-1224$

20. Umubyeyi AN, Rigouts L, Zissis G, Kamanzi E, Pauwels P, et al. (2007) [Primary and acquired resistance to antituberculous drugs in strains of $\mathrm{MyCO}$ bacterium tuberculosis isolated in Rwanda]. Med Trop (Mars) 67: 149-153.

21. Affolabi D, Adjagba OA, Tanimomo-Kledjo B, Gninafon M, Anagonou SY, et al. (2007) Anti-tuberculosis drug resistance among new and previously treated pulmonary tuberculosis patients in Cotonou, Benin. Int $\mathrm{J}$ Tuberc Lung Dis 11:1221-1224.

22. Asiimwe BB, Ghebremichael S, Kallenius G, Koivula T, Joloba ML (2008) Mycobacterium tuberculosis spoligotypes and drug susceptibility pattern of isolates from tuberculosis patients in periurban Kampala, Uganda. BMC Infect Dis 8: 101

23. Suárez PG, Floyd K, Portocarrero J, Alarcón E, Rapiti E, et al. (2002) Feasibility and cost-effectiveness of standardised second-line drug treatment for chronic tuberculosis patients: a national cohort study in Peru. Lancet 359: 1980-1989.

24. World Health Organization (2006) Guidelines of the programmatic management of drug-resistant tuberculosis. World Health Organization, Geneva, Switzerland.

25. Heldal E, Arnadottir T, Cruz JR, Tardencilla A, Chacon L (2001) Low failure rate in standardised retreatment of tuberculosis in Nicaragua: patient category, drug resistance and survival of 'chronic' patients. Int J Tuberc Lung Dis 5: $129-136$.

26. World Health Organization (2008) Anti-tuberculosis resistance in the world World Health Organization, Geneva, Switzerland. 